\title{
Influence of cement-augmented pedicle screws with different volumes of polymethylmethacrylate in osteoporotic lumbar vertebrae over the adjacent segments: a 3D finite element analysis
}

Hui-zhi Guo ${ }^{1,2}$, Shun-cong Zhang ${ }^{1,2}$, Dan-qing Guo ${ }^{1}$, Yan-huai Ma ${ }^{1,2}$, Kai Yuan², Yong-xian Li 1,2, Jian-cheng Peng ${ }^{1,2}$, Jing-lan Li ${ }^{1}$, De Liang ${ }^{2}$ and Yong-chao Tang ${ }^{2 *}$ (D)

\begin{abstract}
Background: Polymethylmethacrylate (PMMA) is commonly used for cement-augmented pedicle screw instrumentation (CAPSI) to improve the fixation stability and reduce the risk of screw loosening in the osteoporotic thoracolumbar spine. Biomechanical researches have shown that various dose of cement (1-3 ml) can be injected to enhance screw stability. To date, there have been no studies on the relationship between adjacent segment degeneration and the volume of PMMA. This study aimed to explore the influence of CAPSI with different volumes of PMMA in osteoporotic lumbar vertebrae over adjacent segments by using finite element analysis.
\end{abstract}

Methods: Seven different finite element models were reconstructed and simulated under different loading conditions, including (1) an intact model, (2) three single-level CAPSI models with different volumes of PMMA (1, 1.73, and $2.5 \mathrm{ml})$, and (3) three double-level CAPSI models with different volumes of PMMA (1, 1.73, and $2.5 \mathrm{ml})$. To improve the accuracy of the finite element analysis, the models of the injectable pedicle screw and bone cement were created by using a threedimensional scanning machine and the CAPSI patient's $\subset T$ data, respectively. The range of motion (ROM), the stress of intervertebral discs, and the stress of facet in the adjacent segment were comparatively analyzed among the different models.

Results: The ROMs of the different segments were compared with experimental data, with good agreement under the different load conditions $\left(21.3^{\circ}, 13.55^{\circ}, 13.99^{\circ}\right.$, and $6.11^{\circ}$ in flexion, extension, bending, and rotation at L3-S1 level, respectively). Compared with the intact model, the ROM, disc stresses, and facet stress in adjacent segments were found to be higher in the six operative models. Otherwise, with a larger volume of PMMA injected, the ROM, disc stresses, and facet stress slightly increased at the adjacent segment. However, the differences were insignificant with the biggest difference less than $3.8 \%$.

*Correspondence: 1114930308@qq.com

${ }^{2}$ Spine Surgery Department, The First Affiliated Hospital of Guangzhou University of Chinese Medicine, Guangzhou 510407, China

Full list of author information is available at the end of the article

(c) The Author(s). 2020 Open Access This article is licensed under a Creative Commons Attribution 4.0 International License, which permits use, sharing, adaptation, distribution and reproduction in any medium or format, as long as you give appropriate credit to the original author(s) and the source, provide a link to the Creative Commons licence, and indicate if changes were made. The images or other third party material in this article are included in the article's Creative Commons licence, unless indicated otherwise in a credit line to the material. If material is not included in the article's Creative Commons licence and your intended use is not permitted by statutory regulation or exceeds the permitted use, you will need to obtain permission directly from the copyright holder. To view a copy of this licence, visit http://creativecommons.org/licenses/by/4.0/ The Creative Commons Public Domain Dedication waiver (http://creativecommons.org/publicdomain/zero/1.0/) applies to the data made available in this article, unless otherwise stated in a credit line to the data. 
(Continued from previous page)

Conclusions: CAPSI could increase the incidence of disk degeneration in the adjacent segment, while within a certain range, different volumes of PMMA provided an approximate impact over the adjacent segment degeneration.

Keywords: Cement-augmented pedicle screws, Adjacent segment degeneration, Polymethylmethacrylate, Finite element analysis

\section{Background}

Posterior lumbar interbody fusion, the classic surgical procedure to treat lumbar degenerative diseases and thoracolumbar fracture, has been developed for more than 70 years since the initial description in 1944 by Briggs and Milligan [1]. A large number of clinical studies have indicated that posterior-approach fusion and fixation can effectively restore sagittal alignment, achieve immediate postoperative stability, and facilitate fusion rates [2-4]. However, consensus holds that the stiffness of the instrument relates directly to increased stress on the adjacent disc and facet joints, which could trigger segmental hypermobility and accelerate adjacent segment degeneration (ASD) $[5,6]$.

ASD is one of the most common sequelae of spinal interbody fusion and affects the patient's long-term results. It is usually considered that radiographic degeneration and/or symptomatic degeneration occurs in the upper or lower adjacent segment. The annual incidence of ASD was reported to be approximately $9.8-86.1 \%$ in the literature $[7,8]$. Studies have shown that advancing age is an independent risk factor for ASD and that aging patients have more obvious degenerative discs, with associated symptoms. In addition, cement-augmented pedicle screw instrumentation (CAPSI) has often been used in elderly people with osteoporosis to increase the pullout strength of the interface between pedicle screws and cancellous bone. None of the previous studies have dealt with biomechanical comparisons of different volumes of polymethylmethacrylate (PMMA) used in osteoporotic lumbar vertebrae over adjacent segments.

The aim of this study was to develop a non-linear finite element (FE) model capable of simulating osteoporotic and fused lumbar spine biomechanics. The purpose is to describe how the PMMA volume used in single- or double-level fixation alters the adjacent discs behavior. Seven different finite element models were generated to compare the range of motion (ROM) and the stress of the intervertebral disc in the adjacent segment, including (1) an intact model, (2) three single-level CAPSI models with different volumes of PMMA (1, 1.73, and $2.5 \mathrm{ml}$ ), and (3) three double-level CAPSI models with different volumes of PMMA (1, 1.73, and $2.5 \mathrm{ml})$.

\section{Methods}

Development of the intact lumbosacral model

In this study, a healthy adult female volunteer without any history of spinal diseases was selected and the data of her CT scans (AQUIRRON 64, Toshiba, Japan, 250 $\mathrm{mAs}, 120 \mathrm{kV}$ voltage, slice thickness of $0.625 \mathrm{~mm}$ ) was obtained from the department of radiology of our hospital. The computed tomography scan images were stored in Digital Imaging and Communications in the Medicine (DICOM) format.

Anatomical 3D models of the lower lumbar vertebrae, sacrum, and coccyx were generated using Mimics research 19.0 (Materialize, Leuven, Belgium). Subsequently, the rough spinal model was imported into Geomagic Studio 2013 (3D Systems Corporation, South Carolina, USA) for further operation, including delete the spikes and the features, making triangles more uniform in size, and generate the surface model. The smoothed model was processed using SolidWorks 2017CAD (SolidWorks Corporation, Concord, MA, USA). Cortical bone, cancellous bone, nucleus pulposus, annulus fibrosus, facet cartilage, and vertebral endplates parts were constructed subsequently. The nucleus pulposus, simulated as a fluid-like and incompressible material, occupied $44 \%$ of the disc volume [9]. The thickness of the cortical bone was approximately 0.5 $\mathrm{mm}$ [9], and the cartilaginous endplates were modeled to be approximately $1 \mathrm{~mm}$ thick $[10,11]$. The initial gap between the articulating surfaces was based on computed tomography images and was approximately $0.3-0.6 \mathrm{~mm}$. The above parts were assembled into an intact lumbosacral model.

\section{Three-dimensional scanning models of pedicle screw}

The 3D scanner (Solutionix Rexcan CS+ 3D scanner, SolutioniX, Korea) was applied to scan and build the model of the pedicle screw. The instrument used image registration and $3 \mathrm{D}$ matching technology to create a point cloud of the geometric surface by a surface scanning of the target object. Then, the geometric model is generated automatically by the software. Steps to reconstructed the model were as follows: first, the surface of the fenestrated pedicle screw was sprayed with the developer evenly; after that, Ezscan 2017 software was applied to scan the fixed screws automatically; after finishing the scanning, the redundant parts of the 3D 

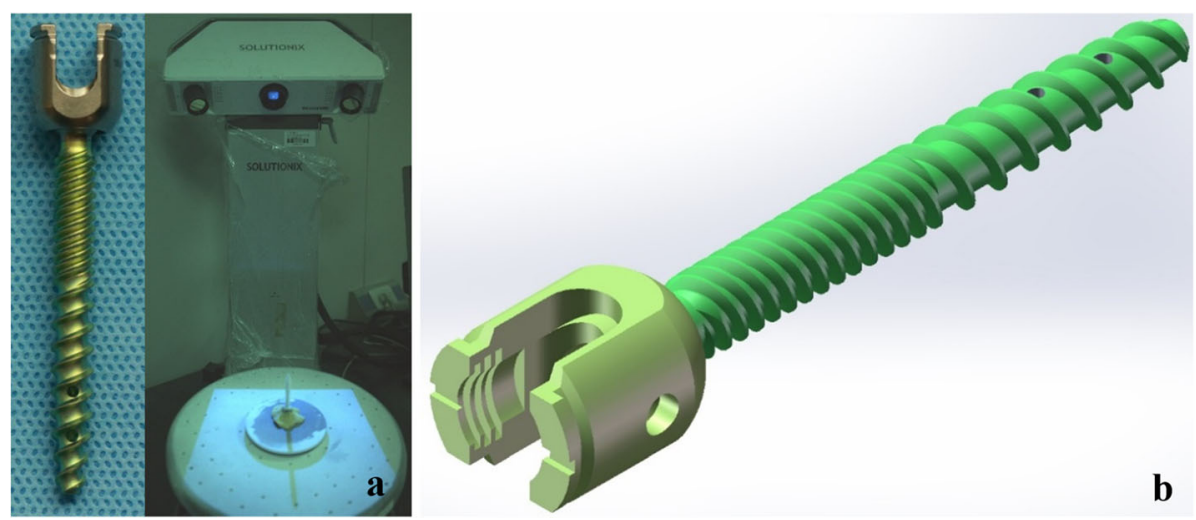

Fig. 1 a The fenestrated pedicle screw material and picture of the 3D scanner working; $\mathbf{b}$ the model of the fenestrated pedicle screw

models were deleted using the lasso tool, and the file was saved in STL format.

The 3D models generated by the scanner were imported into Geomagic Studio 2013 and SolidWorks 2017CAD for further processing. Finally, the models with realistic geometry were used for the assembly of surgical models. The length and outer diameter of the pedicle screws (DePuy Synthes, California, USA) were 50 and $6.0 \mathrm{~mm}$, respectively (Fig. 1).

\section{The model of bone cement}

By using a random number table of CAPSI patients, a patient who was undergone fenestrated pedicle screw with cement-augmented was randomly selected from the table. The cement model was constructed by using the postoperative lumbar CT data through the above software. The volume of bone cement was approximately $1.73 \mathrm{~cm}^{3}$ and distributed in a lump pattern. Then, the cement model with $1.73 \mathrm{ml}$ PMMA was scaled to $1 \mathrm{ml}$ and $2.5 \mathrm{ml}$.

\section{Construction of instrument models with different volumes of PMMA}

The models of cage and rod were constructed in the SolidWorks 2017CAD according to the physical cage and rod. The outer diameter of the rod was $5.5 \mathrm{~mm}$. The length and height of the cage were 24 and $12 \mathrm{~mm}$. Subsequently, unilateral transforaminal lumbar interbody fusion (TLIF) was assumed in right to remove the facet joint, facet cartilage, part of the annulus fibrosus, cartilaginous endplate, and nucleus. The screws, cement, rod, and cage were integrated with the lumbosacral model to construct six surgical models. The interbody cage is
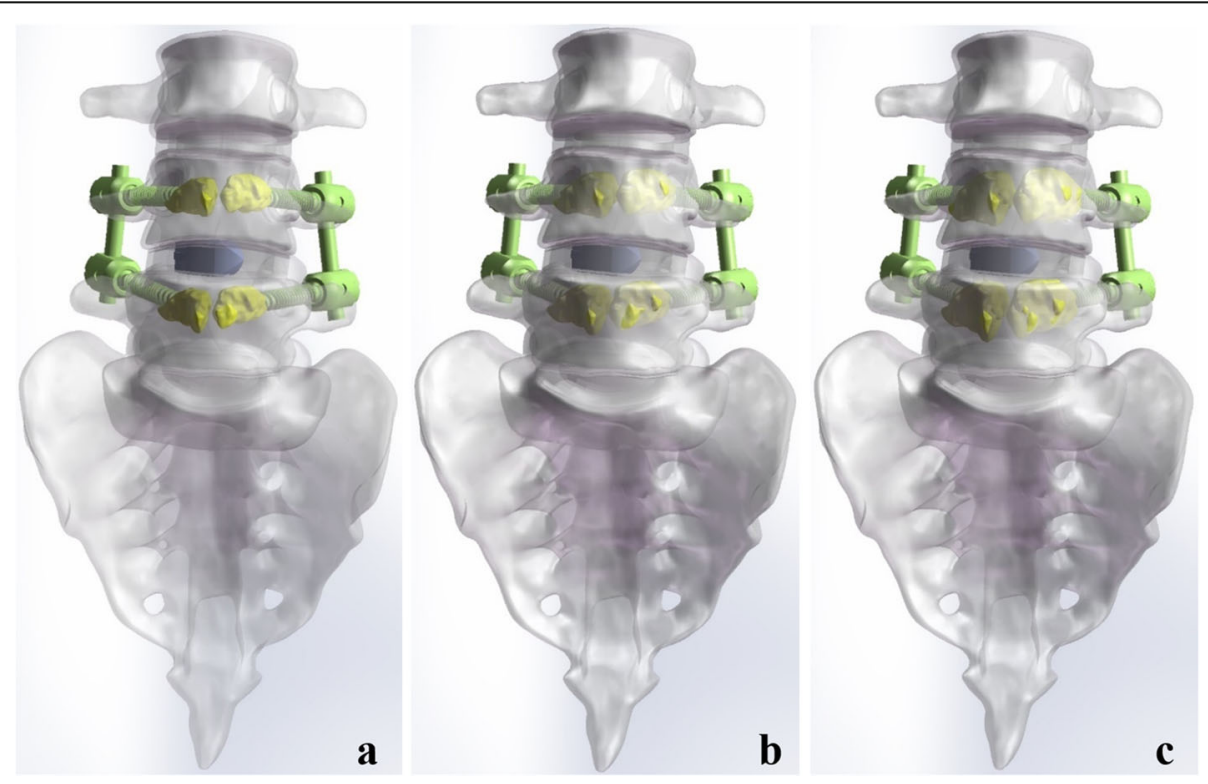

Fig. 2 The models of CAPSI following single-level lumbar interbody fusion (a) $1.0 \mathrm{ml}$ PMMA per screw; b $1.73 \mathrm{ml}$ PMMA per screw; c $2.5 \mathrm{ml}$ PMMA per screw 

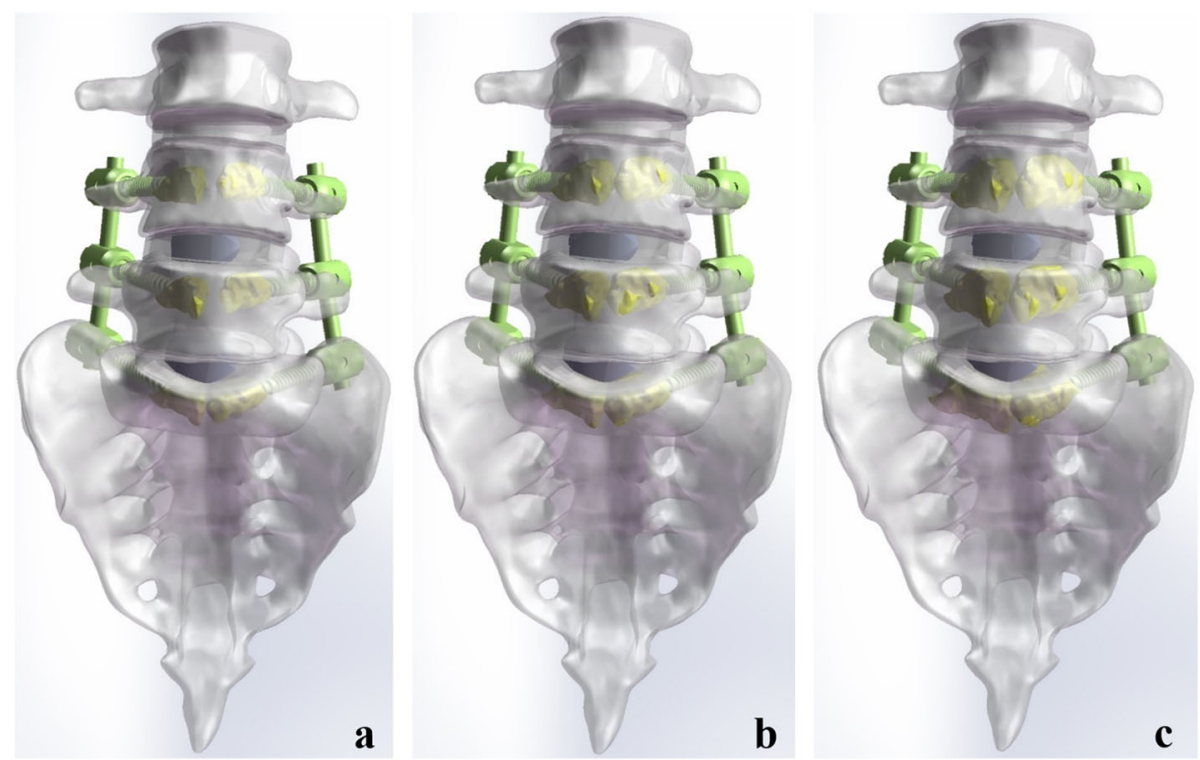

Fig. 3 The models of CAPSI following double-level lumbar interbody fusion (a) $1.0 \mathrm{ml}$ PMMA per screw; b $1.73 \mathrm{ml}$ PMMA per screw; c $2.5 \mathrm{ml}$ PMMA per screw

placed in the center of the intervertebral space. To control variables and maintain consistency, the consistent location of cages, screws, rods, and bone cement were used in the different surgical models (Figs. 2 and 3).

\section{Loading and boundary conditions}

All the FE model was imported into ANSYS Workbench 17.0 (ANSYS, Ltd., Canonsburg, Pennsylvania, USA) for biomechanical testing. The material properties of cortical bone (osteoporosis), cancellous bone (osteoporosis), endplates, nucleus pulposus, annulus fibrosus, facet cartilage, cages, bone cement, and posterior spinal instrumentation was set according to previous studies (Table 1) [10, 12, 13]. The ligaments of the spine were simulated using tension-only and nonlinear spring elements [14]. The contact type of the facet joint was defined as "frictional", and the friction coefficient was set at 0.1 . The remaining bodies were defined as the "bonded" mode [11]. To reach a more accurate calculation, the tetrahedron mesh was used and the character of mesh was set up according to previous reports: the dimension of the joint cartilage mesh was $0.5 \mathrm{~mm}$, while that of the other bodies was $2.0 \mathrm{~mm}$. Finally, the loading and boundary conditions of the six surgical models were set up $[10,13]$ : The sacroiliac joint was bilaterally fixed with all degrees of moment restricted throughout the whole analysis. a vertical compressive force of $150 \mathrm{~N}$ was used on the upper surface of L3, and a 10 $\mathrm{Nm}$ moment was applied along the radial direction in flexion, extension, left lateral bending, right lateral bending, left rotation, and right rotation. The ROM, the disc stress at L3-4, and inferior articular process

Table 1 Material properties used in finite-element model

\begin{tabular}{|c|c|c|}
\hline Material Properties & $\begin{array}{l}\text { Young's Modulus (E: } \\
\mathrm{MPa} \text { ) }\end{array}$ & $\begin{array}{l}\text { Poisson's Ratio } \\
(\mu)\end{array}$ \\
\hline Osteoporotic cortical bone & 8040 (67\% of normal) & 0.3 \\
\hline Osteoporotic cancellous bone & 34 (34\% of normal) & 0.2 \\
\hline Cartilage & 50 & 0.3 \\
\hline Endplate & 1000 & 0.3 \\
\hline Annulus fibrosus & 4.2 & 0.45 \\
\hline Nucleus pulposus & 1 & 0.499 \\
\hline \multicolumn{3}{|l|}{ Ligament } \\
\hline Anterior longitudinal & 20 & 0.3 \\
\hline Posterior longitudinal & 20 & 0.3 \\
\hline Transverse & 59 & 0.3 \\
\hline Ligamentum flavum & 19.5 & 0.3 \\
\hline Interspinous & 12 & 0.3 \\
\hline Supraspinous & 15 & 0.3 \\
\hline Capsular ligament & 7.5 & 0.3 \\
\hline $\begin{array}{l}\text { Spinal instrumentation (titanium } \\
\text { alloy) }\end{array}$ & 110,000 & 0.28 \\
\hline Bone cement (PMMA) & 3000 & 0.4 \\
\hline $\begin{array}{l}\text { Spinal cage } \\
\text { (polyetheretherketone) }\end{array}$ & 3600 & 0.25 \\
\hline
\end{tabular}

PMMA Polymethylmethacrylate 
Table 2 Comparison of ROM between the intact model and the in vitro study at different levels

\begin{tabular}{lllll}
\hline & Flexion & Extension & Bending & Rotation \\
\hline L3-L4 $\left(^{\circ}\right)$ & & & & \\
The intact model & 6.66 & 5.41 & 5.33 & 1.64 \\
Yamamoto et al & 6.1 & 3.89 & 4.3 & 1.9 \\
$\begin{array}{l}\text { L4-L5 }\left(^{\circ}\right) \\
\text { The intact model }\end{array}$ & 7.29 & 4.19 & 5.23 & 2.61 \\
Yamamoto et al & 7.1 & 4 & 4.1 & 1.8 \\
L5-S1 $\left(^{\circ}\right)$ & & & & \\
The intact model & 7.35 & 3.95 & 3.43 & 1.86 \\
Yamamoto et al & 7 & 4.8 & 3.7 & 1.00 \\
\hline
\end{tabular}

stress at L3 were recorded to make a biomechanical comparison of different volumes of PMMA in adjacent segments.

\section{Results}

We compared our range of motion (ROM) results with those experimental data conducted by Yamamoto et al. [15]. The ROMs of different segments were in accordance with the previous literature under flexionextension, lateral bending, and rotation loads (Table 2).

\section{Range of motion}

As shown in Fig. 4, the instability of the adjacent disc was accentuated by the CAPSI. The ROM at L3-4 increased in all motion cases to compensate for the reduction in the fixed segment. With the increased volume of PMMA, this effect was slightly magnified, reaching the highest ROM in flexion movement for both the single- and double-level lumbar interbody fusion models (Fig. 4). The variation of

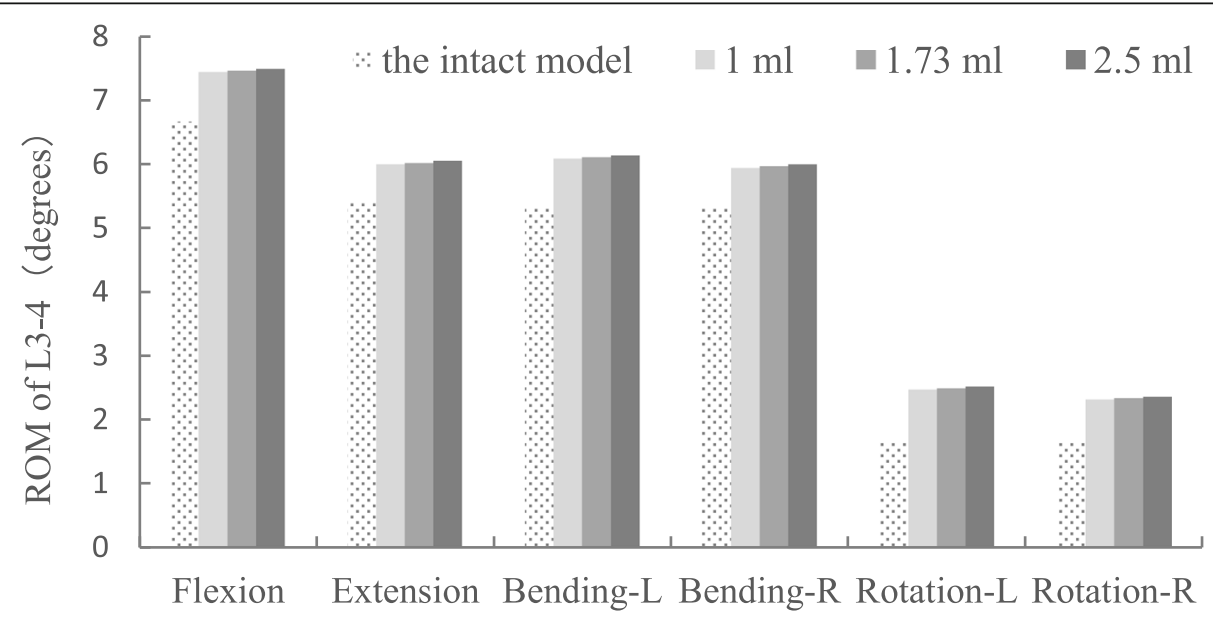

a

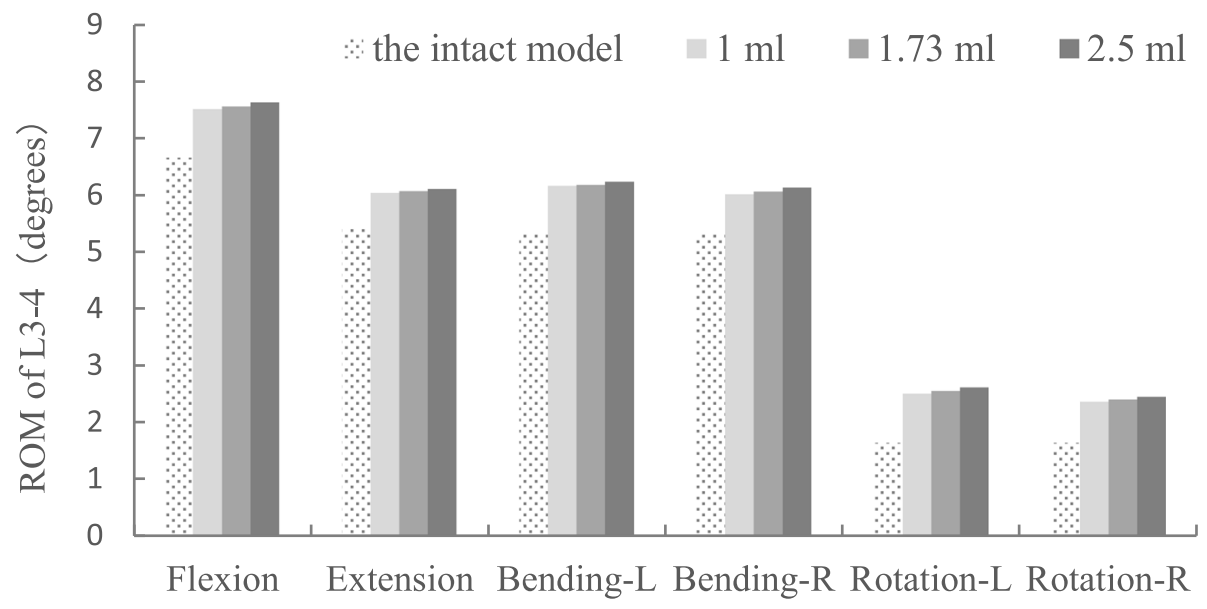

b

Fig. 4 The ROM of adjacent segments following single (a) and double-level (b) lumbar spinal fusion 
ROMs in the double-level lumbar interbody fusion models was more evident, particularly in rotation. The calculated data showed that the ROM at L3-4 was nearly unaffected by different volumes of PMMA in both single-level and double-level fusion models.

\section{Stress of the disc}

Attending to the peak von Mises stress of the disc, compared with the surgical models, the disc stress for the intact model was still lower in all motion modes. Flexion and lateral bending movement were the worst motion modes in CAPSI models, as in the ROM analysis, for the upper adjacent disc. Although the disc stress increased in the CAPSI models under all loading conditions, the results were similar for different volumes of PMMA. The results showed that the PMMA volume did not have a significant effect on the adjacent disc (Fig. 5). The peak von Mises stress of the disc in the double-level
CAPSI model with different volumes of PMMA (1, 1.73, and $2.5 \mathrm{ml}$ ) were calculated and are shown in Fig. 6.

\section{The stress of facet}

The maximum stress in the inferior articular process (L3) is displayed in Fig. 7. The facet stress of surgical models was slightly higher than that of the intact model. Similarly, with a higher dose of injected PMMA, the facet stress was increased, while the gap among different models was still narrowed.

\section{Discussion}

With advances in surgery and anesthesia, posterior lumbar fusion and pedicle screw instrumentation have been used progressively more often in aged patients with lumbar degenerative disease by spine surgeons. However, screw loosening, migration, and back-out is the most common postoperative complication of the pedicle screw, which usually results in painful nonunion,
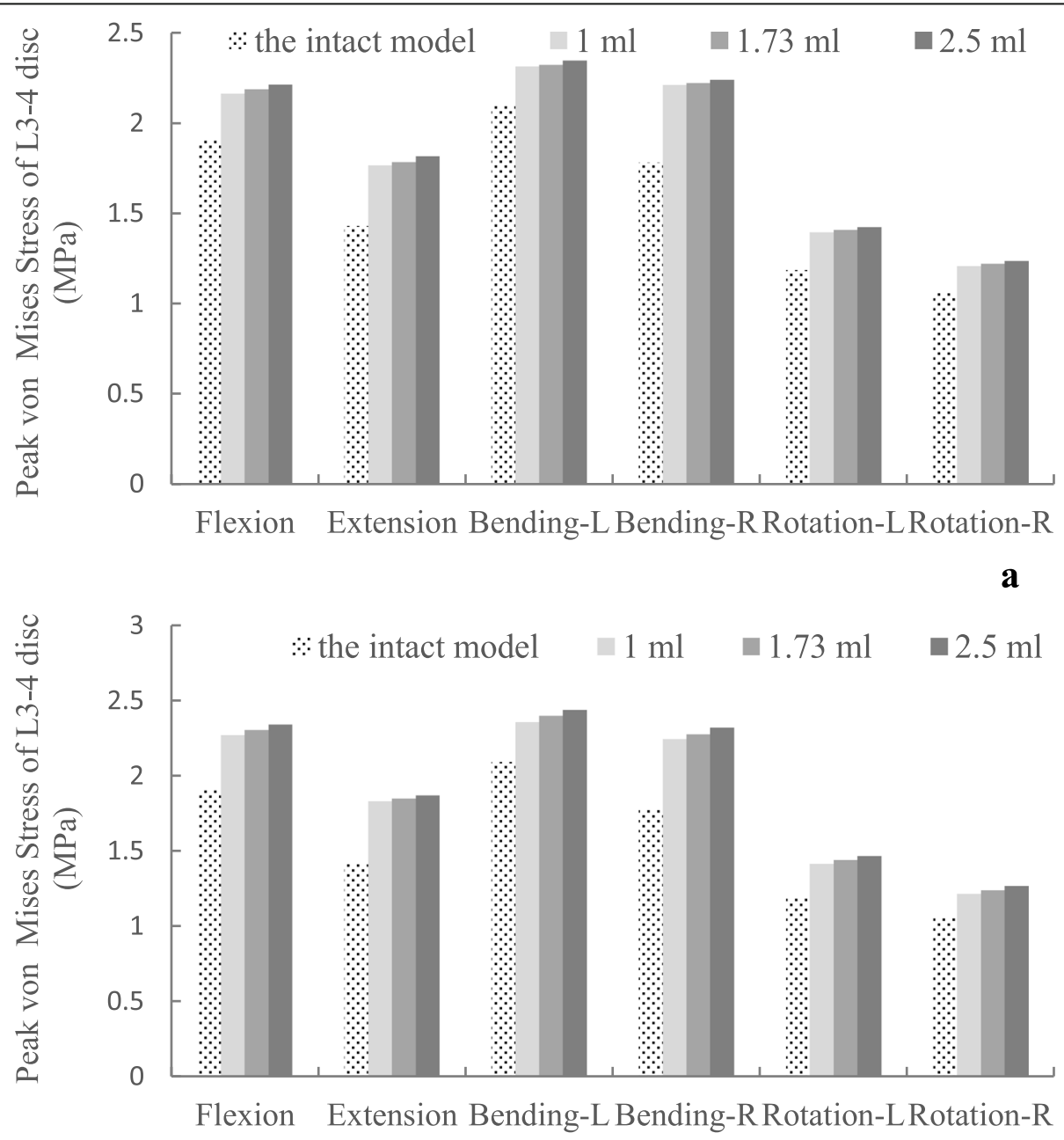

b

Fig. 5 The disc stress of adjacent segments following single (a) and double-level (b) lumbar spinal fusion 


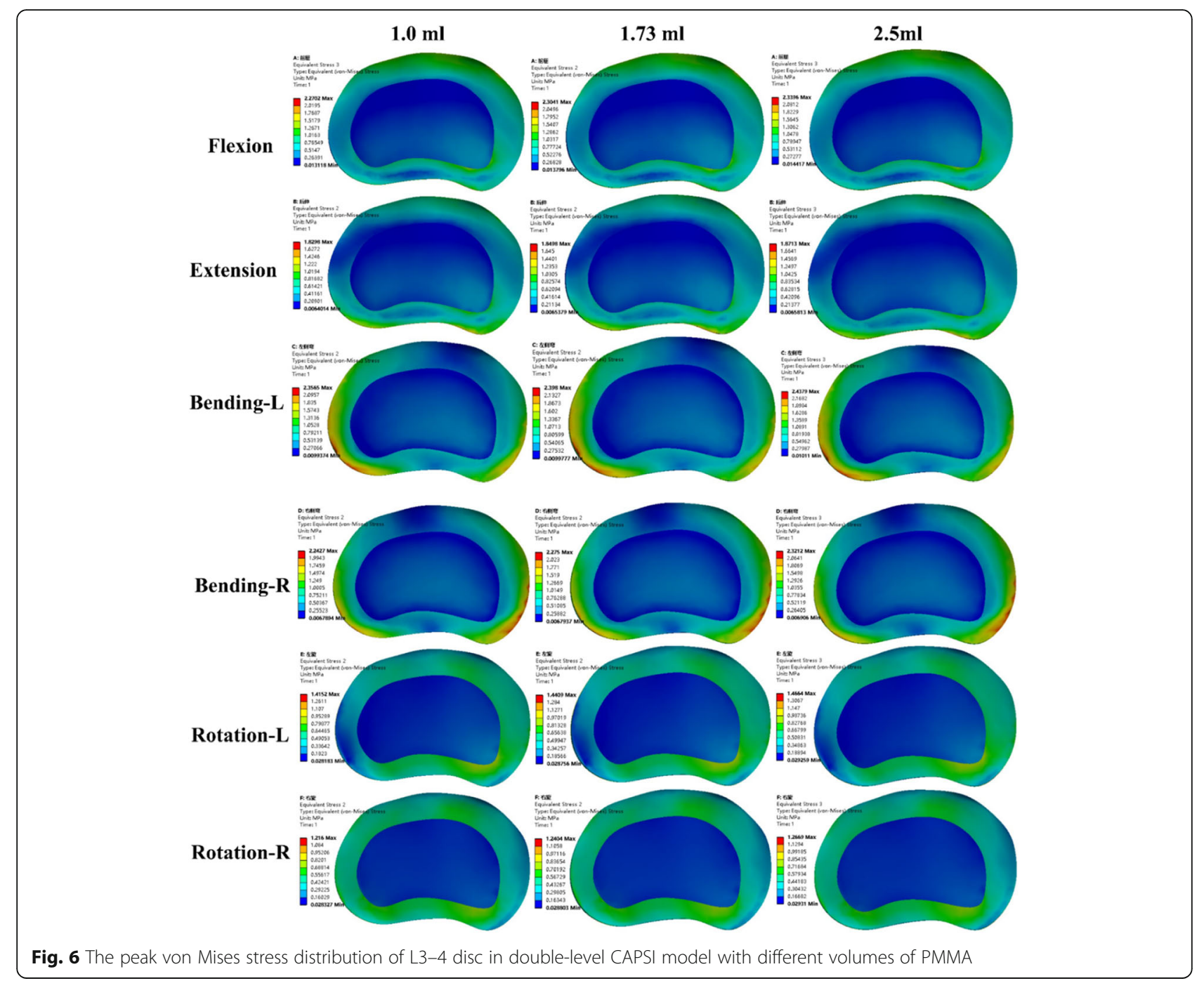

progressive kyphosis, and revision surgery [16]. Clinical studies have reported an overall instrumentation failure rate of 1 to $15 \%$ in ordinary patients, even 10 to $62.8 \%$ in patients with osteoporosis [17-20]. Reports in the surgical literature indicate that CAPSI has been widely used to enhance fixation strength to improve pedicle screw stability in osteoporotic spines [21]. However, previous reports also showed that a rigid instrument may grossly alter the physiologic load transmission at the instrumented level and has a cascading degenerative effect over the adjacent discs $[22,23]$.

It is generally agreed that ASD can be divided into radiologic adjacent segment degeneration (ASDeg) and adjacent segment disease (ASDis). Studies have documented a rate of clinical ASDis between 2 and $12.2 \%$ at different follow-up periods [24, 25]. For patients with ASDis who underwent revision, the satisfaction rate was approximately only $54 \%$, which is significantly lower than that of other patients (83\%) [26]. In addition, the initial disc degeneration of adjacent segments in elderly patients was more severe than that in younger patients, which has been reported to increase the incidence of ASD. Thus, for the study we report here, we planned to clarify the effect of different volumes of PMMA on ASD among aged patients and to provide a useful reference to spinal surgeons when considering CAPSI for early patients.

Finite element analysis can accurately characterize the complex biomechanical mechanism of the spine and clearly show the stress distribution of each part. Proper geometric characteristics of models are essential for the accurate outcome of FE analysis. In previous finite element studies, the three-dimensional solid models of the pedicle screw and bone cement were constructed by using SolidWorks or Hypermesh software [27, 28], which cannot accurately simulate the characteristics of the material object. Therefore, in the current study, the threaded pedicle screw (Fig. 1) and lumpy bone cement were constructed to be realistic with a 3D scanner and 

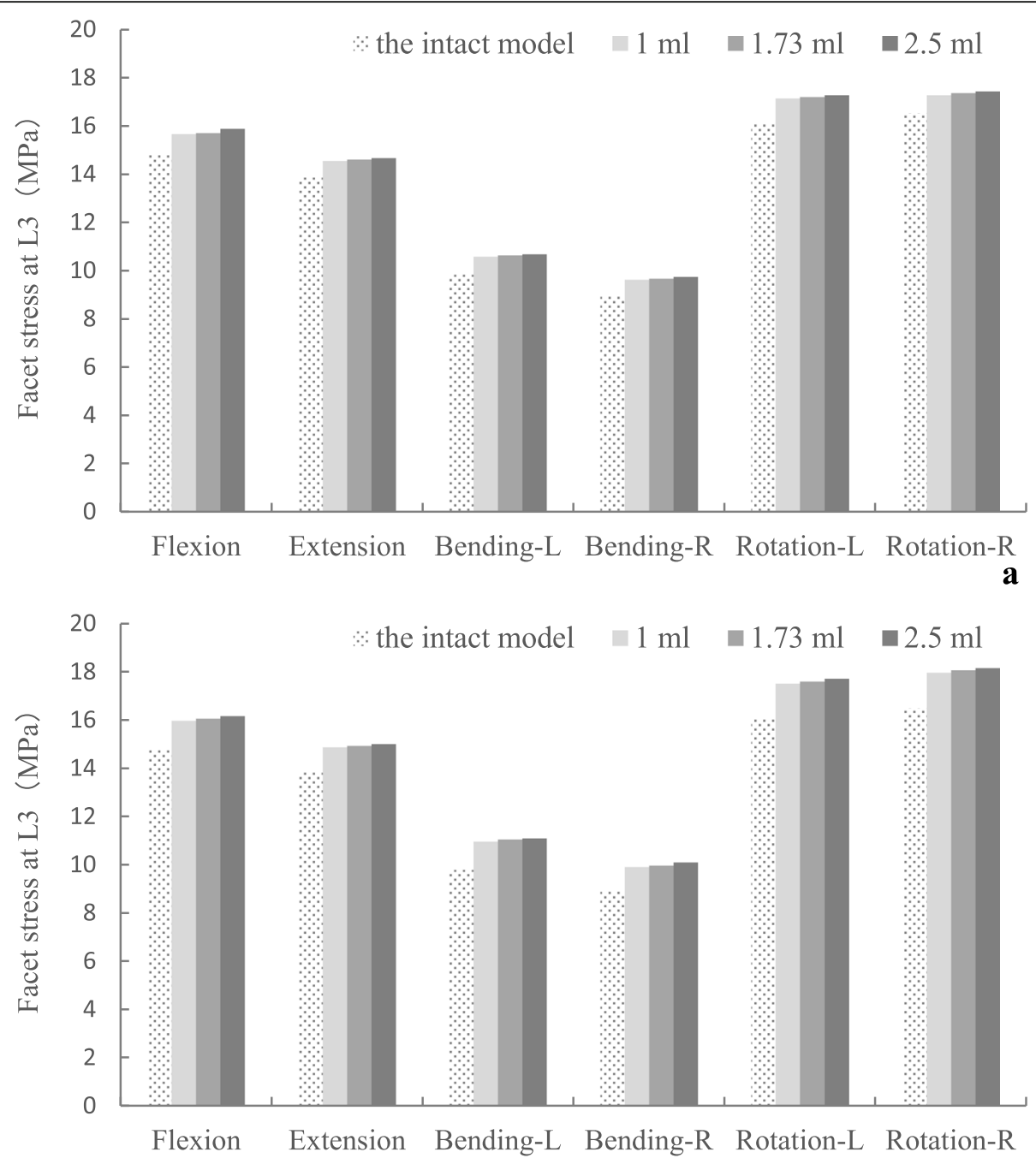

Fig. 7 The facet stress of adjacent segments following single (a) and double-level (b) lumbar spinal fusion

the patient's CT data, respectively. In addition, lumbar degenerative diseases such as lumbar spinal stenosis occur mostly in the L4-S1 segment. Biomechanical experiments found that both solid and fenestrated screws can significantly increase the pull-out force in cementaugmented pedicle screw fixation [16]. And fenestrated screws were used more commonly in CAPSI. Thus, this study used a model of L4-5/ L4-S1 segmental fusion and fenestrated screws fixed to analyze the effect of the volume of PMMA after CAPSI.

In this study, to distinguish the influence in the adjacent discs, the ROM, disc stress, and facet stress were compared with the intact value. An increase in the ROM, disc stress, and facet stress were found in adjacent segments in all loading directions that were more pronounced in the double-level CAPSI model with $2.5 \mathrm{ml}$ PMMA (the increasing stress on disc and facet may be related to the increasing segmental instability). However, the variation in single- and double-level CAPSI models was similar for various volumes of PMMA $(1 \mathrm{ml}, 1.73$ $\mathrm{ml}$, and $2.5 \mathrm{ml})$. Although CAPSI increases the risk of adjacent segment degeneration, this study did not find meaningful associations between ASD incidence and the volumes of PMMA. Otherwise, experimental data have reported that a cement volume between 1.0 and $3.0 \mathrm{ml}$ significantly improves screw stability, whereas a volume beyond $3.0 \mathrm{ml}$ does not increase the purchasing strength linearly but results in an increase of cement leakage [21, 29]. Therefore, within a certain range, increasing the volume of PMMA does not significantly affect the stability of adjacent segments, and PMMA volumes between 1.0 $\mathrm{ml}$ and $2.5 \mathrm{ml}$ can be selectively used according to different degrees of osteoporosis.

This computational study was based on finite element analysis and has some limitations. First, because the scanning accuracy of the 3D scanner in the uneven and 
subtle parts of the screw (such as the screw thread) is insufficient, further processing is required in the scanned models by Geomagic Studio 2013 and SolidWorks software, and the extra processing may result in a modicum of distortion in the model. Furthermore, several simplifications were necessary for creating the finite element model, such as the characteristics of ligaments, paraspinal muscles, and body weight, which also limited the results. Otherwise, it is difficult to accurately simulate the interaction between trabecular bone and bone cement. Therefore, further cadaver studies and clinical observations are necessary to reach a more precise conclusion.

\section{Conclusion}

The observed results suggested that CAPSI could increase the incidence of disk degeneration in the adjacent segment, while within a certain range, different volumes of PMMA provided an approximate impact over the adjacent segment degeneration. Clinically, PMMA volumes between $1.0 \mathrm{ml}$ and $2.5 \mathrm{ml}$ can be selectively used according to different degrees of osteoporosis.

\section{Abbreviations}

PMMA: Polymethylmethacrylate; CAPSI: Cement-augmented pedicle screw instrumentation; ASD: Adjacent segment degeneration; ROM: Range of motion; FEA: Finite element analysis; TLIF: Transforaminal lumbar interbody fusion; ASDis: Adjacent segment disease

\section{Acknowledgements}

The authors thank the Department of Digital Orthopedics and Biomechanics Laboratory at Guangzhou University of Chinese Medicine for his help in the experimental studies.

\section{Authors' contributions}

HG and SZ conceived the study, designed the study, drafted the manuscript and had the overall scientific responsibility. DG, YM, and KY constructed the finite element models, performed the biomechanical analysis. $Y \mathrm{~L}, J \mathrm{P}$, JL, and DL participated in discussion of the clinical results. All authors contributed to the paper revision, read and approved the final manuscript.

\section{Funding}

This study supported by National Construction of High-quality University Project, the project of Traditional Chinese Medicine Bureau of Guangdong Provincial (20203004), and the innovation and strength project of The First Affiliated Hospital of Guangzhou University of Chinese Medicine (2019|1T32). The authors have no personal financial or institutional interest in any of the drugs, materials, or devices described in this article.

\section{Availability of data and materials}

The datasets used and/or analyzed during the current study are available from the corresponding author upon reasonable request.

\section{Ethics approval and consent to participate}

This study was approved by the Ethics Committee of The First Affiliated Hospital of Guangzhou University of Chinese Medicine.

The participation in the study was voluntary and written informed consent was obtained from the participants.

\section{Consent for publication}

Not applicable.

\section{Competing interests}

The authors declare that they have no competing interests.

\section{Author details}

${ }^{1} T$ The 1st Institute of Clinical Medicine, Guangzhou University of Chinese Medicine, 12 Airport Road, Baiyun District, Guangzhou 510407, Guangdong, People's Republic of China. ${ }^{2}$ Spine Surgery Department, The First Affiliated Hospital of Guangzhou University of Chinese Medicine, Guangzhou 510407, China.

Received: 31 January 2020 Accepted: 10 July 2020

Published online: 13 July 2020

\section{References}

1. Albee FH. Transplantation of a portion of the tibia into the spine for Pott's disease: a preliminary report 1911. Clin Orthop Relat Res. 2007:460:14-6. https://doi.org/10.1097/BLO.0b013e3180686a0f.

2. Le Huec JC, Thompson W, Mohsinaly Y, Barrey C, Faundez A. Sagittal balance of the spine. Eur Spine J. 2019;28:1889-905. https://doi.org/10.1007/ s00586-019-06083-1.

3. Shirahata T, Okano I, Salzmann SN, Sax OC, Shue J, Sama AA, et al. The Association between Surgical Level and Early Postoperative Thigh Symptoms among Patients Undergoing Standalone Lateral Lumbar Interbody Fusion (LLIF). World Neurosurg. 2019. https://doi.org/10.1016/j. wneu.2019.11.025.

4. Tong YJ, Liu JH, Fan SW, Zhao FD. One-stage debridement via oblique lateral interbody fusion corridor combined with posterior pedicle screw fixation in treating spontaneous lumbar infectious spondylodiscitis: a case series. Orthop Surg. 2019. https://doi.org/10.1111/os.12562.

5. Li C, He Q, Tang Y, Ruan D. The fate of adjacent segments with pre-existing degeneration after lumbar posterolateral fusion: the influence of degenerative grading. Eur Spine J. 2015;24:2468-73. https://doi.org/10.1007/ s00586-015-3921-2.

6. Ramirez-Villaescusa J, López-Torres Hidalgo J, Martin-Benlloch A, Ruiz-Picazo D, Gomar-Sancho F. Risk factors related to adjacent segment degeneration: retrospective observational cohort study and survivorship analysis of adjacent unfused segments. Br J Neurosurg. 2019;33:17-24. https://doi.org/ 10.1080/02688697.2018.1523365

7. Nakashima H, Kawakami N, Tsuji T, Ohara T, Suzuki Y, Saito T, et al. Adjacent Segment Disease After Posterior Lumbar Interbody Fusion: Based on Cases With a Minimum of 10 Years of Follow-up. Spine (Phila Pa 1976). 2015;40: E831-41. https://doi.org/10.1097/BRS.0000000000000917.

8. Kim JY, Ryu DS, Paik HK, Ahn SS, Kang MS, Kim KH, et al. Paraspinal muscle, facet joint, and disc problems: risk factors for adjacent segment degeneration after lumbar fusion. Spine J. 2016;16:867-75. https://doi.org/ 10.1016/.spinee.2016.03.010.

9. Wang Md K, Jiang PhD C, Wang PhD L, Wang Md H, Niu PDW. The biomechanical influence of anterior vertebral body osteophytes on the lumbar spine: a finite element study. Spine J. 2018;18:2288-96. https://doi. org/10.1016/j.spinee.2018.07.001.

10. Xu H, Ju W, Xu N, Zhang X, Zhu X, Zhu L, et al. Biomechanical comparison of transforaminal lumbar interbody fusion with 1 or 2 cages by finiteelement analysis. Neurosurgery. 2013;73:ons198-205; discussion ons 205. https://doi.org/10.1227/01.neu.0000430320.39870.f7.

11. Lu T, Lu Y. Comparison of biomechanical performance among Posterolateral fusion and Transforaminal, extreme, and oblique lumbar Interbody fusion: a finite element analysis. World Neurosurg. 2019;129:e890-890e899. https:// doi.org/10.1016/j.wneu.2019.06.074.

12. Shim CS, Park SW, Lee SH, Lim TJ, Chun K, Kim DH. Biomechanical evaluation of an interspinous stabilizing device, Locker. Spine (Phila Pa. 1976). 2008;33:E820-7. https://doi.org/10.1097/BRS.0b013e3181894fb1.

13. Reis MT, Reyes PM, Bse, Altun I, Newcomb AG, Singh V, et al. Biomechanical evaluation of lateral lumbar interbody fusion with secondary augmentation. J Neurosurg Spine. 2016;25:720-6. https://doi.org/10.3171/2016.4. SPINE151386.

14. Wang T, Zhao Y, Cai Z, Wang W, Xia Y, Zheng G, et al. Effect of osteoporosis on internal fixation after spinal osteotomy: A finite element analysis. Clin Biomech (Bristol, Avon). 2019;69:178-83. https://doi.org/10.1016/j. clinbiomech.2019.07.032

15. Yamamoto I, Panjabi MM, Crisco T, Oxland T. Three-dimensional movements of the whole lumbar spine and lumbosacral joint. Spine (Phila Pa 1976). 1989;14:1256-60. https://doi.org/10.1097/00007632-198911000-00020.

16. Chen $L H$, Tai $C L$, Lai PL, Lee DM, Tsai $T$, Fu TS, et al. Pullout strength for cannulated pedicle screws with bone cement augmentation in severely 
osteoporotic bone: influences of radial hole and pilot hole tapping. Clin Biomech (Bristol, Avon). 2009;24:613-8. https://doi.org/10.1016/j. clinbiomech.2009.05.002.

17. Galbusera F, Volkheimer D, Reitmaier S, Berger-Roscher N, Kienle A, Wilke HJ. Pedicle screw loosening: a clinically relevant complication. Eur Spine J. 2015; 24:1005-16. https://doi.org/10.1007/s00586-015-3768-6.

18. Guo HZ, Tang YC, Li YX, Yuan K, Guo DQ, Mo GY, et al. The effect and safety of Polymethylmethacrylate-augmented sacral pedicle screws applied in osteoporotic spine with lumbosacral degenerative disease: a 2-year followup of 25 patients. World Neurosurg. 2019;121:e404-404e410. https://doi.org/ 10.1016/j.wneu.2018.09.121.

19. Leng J, Han G, Zeng Y, Chen Z, Li W. The effect of paraspinal muscle degeneration on distal pedicle screw loosening following corrective surgery for degenerative lumbar scoliosis. Spine (Phila Pa 1976). 2019. https://doi. org/10.1097/BRS.0000000000003336

20. Tanioka S, Ishida F, Kuraishi K, Tanaka K, Shimosaka S, Suzuki H, et al. A novel radiological assessment of screw loosening focusing on spatial position change of screws using an iterative closest point algorithm with stereolithography data: technical note. World Neurosurg. 2019. https://doi. org/10.1016/j.wneu.2018.12.209

21. Liu D, Zhang B, Xie QY, Kang X, Zhou JJ, Wang CR, et al. Biomechanical comparison of pedicle screw augmented with different volumes of polymethylmethacrylate in osteoporotic and severely osteoporotic cadaveric lumbar vertebrae: an experimental study. Spine J. 2016;16:112432. https://doi.org/10.1016/j.spinee.2016.04.015.

22. Cuéllar JM, Lanman TH, Rasouli A. The safety of single and multi-level cervical total disc replacement in ambulatory surgery centers. Spine (Phila Pa 1976). 2019. https://doi.org/10.1097/BRS.0000000000003307.

23. Goedmakers C, Janssen T, Yang X, Arts MP, Bartels R, Vleggeert-Lankamp C. Cervical radiculopathy: is a prosthesis preferred over fusion surgery? A systematic review. Eur Spine J. 2019. https://doi.org/10.1007/s00586-01906175-y.

24. Pan A, Hai Y, Yang J, Zhou L, Chen X, Guo H. Adjacent segment degeneration after lumbar spinal fusion compared with motionpreservation procedures: a meta-analysis. Eur Spine J. 2016;25:1522-32. https://doi.org/10.1007/s00586-016-4415-6.

25. Sakaura H, Ikegami D, Fujimori T, Sugiura T, Mukai Y, Hosono N, et al. Early cephalad adjacent segment degeneration after posterior lumbar interbody fusion: a comparative study between cortical bone trajectory screw fixation and traditional trajectory screw fixation. J Neurosurg Spine. 2019:1-5. https://doi.org/10.3171/2019.8.SPINE19631.

26. Lee JC, Kim Y, Soh JW, Shin BJ. Risk factors of adjacent segment disease requiring surgery after lumbar spinal fusion: comparison of posterior lumbar interbody fusion and posterolateral fusion. Spine (Phila Pa 1976). 2014;39: E339-45. https://doi.org/10.1097/BRS.0000000000000164.

27. Elmasry SS, Asfour SS, Travascio F. Finite element study to evaluate the biomechanical performance of the spine after augmenting percutaneous pedicle screw fixation with kyphoplasty in the treatment of burst fractures. J Biomech Eng. 2018;140. https://doi.org/10.1115/1.4039174.

28. La Barbera L, Cianfoni A, Ferrari A, Distefano D, Bonaldi G, Villa T. Stentscrew assisted internal fixation of osteoporotic vertebrae: a comparative finite element analysis on SAIF technique. Front Bioeng Biotechnol. 2019;7: 291. https://doi.org/10.3389/fbioe.2019.00291.

29. Fölsch C, Goost H, Figiel J, Paletta JR, Schultz W, Lakemeier S. Correlation of pull-out strength of cement-augmented pedicle screws with CT-volumetric measurement of cement. Biomed Tech (Berl). 2012;57:473-80. https://doi. org/10.1515/bmt-2012-0012.

\section{Publisher's Note}

Springer Nature remains neutral with regard to jurisdictional claims in published maps and institutional affiliations.

Ready to submit your research? Choose BMC and benefit from:

- fast, convenient online submission

- thorough peer review by experienced researchers in your field

- rapid publication on acceptance

- support for research data, including large and complex data types

- gold Open Access which fosters wider collaboration and increased citations

- maximum visibility for your research: over $100 \mathrm{M}$ website views per year

At BMC, research is always in progress.

Learn more biomedcentral.com/submissions 